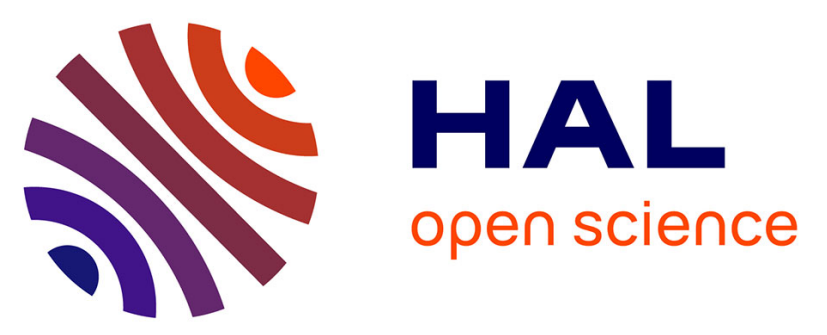

\title{
How recycling mitigates supply risks of critical raw materials: Extension of the geopolitical supply risk methodology applied to information and communication technologies in the European Union
}

Jair Santillán-Saldivar, Alexander Cimprich, Noor Shaikh, Bertrand Laratte, Steven B. Young, Guido Sonnemann

\section{To cite this version:}

Jair Santillán-Saldivar, Alexander Cimprich, Noor Shaikh, Bertrand Laratte, Steven B. Young, et al.. How recycling mitigates supply risks of critical raw materials: Extension of the geopolitical supply risk methodology applied to information and communication technologies in the European Union. Resources, Conservation and Recycling, 2021, 164, pp.105108. 10.1016/j.resconrec.2020.105108 . hal02923949

\author{
HAL Id: hal-02923949 \\ https://hal.science/hal-02923949
}

Submitted on 27 Aug 2020

HAL is a multi-disciplinary open access archive for the deposit and dissemination of scientific research documents, whether they are published or not. The documents may come from teaching and research institutions in France or abroad, or from public or private research centers.
L'archive ouverte pluridisciplinaire HAL, est destinée au dépôt et à la diffusion de documents scientifiques de niveau recherche, publiés ou non, émanant des établissements d'enseignement et de recherche français ou étrangers, des laboratoires publics ou privés. 


\title{
How recycling mitigates supply risks of critical raw materials: Extension of the geopolitical supply risk methodology applied to information and communication technologies in the European Union
}

\author{
Jair Santillán-Saldivar ${ }^{\mathrm{a}, \mathrm{b}, \mathrm{c}}$, Alexander Cimprich $^{\mathrm{c}}$, Noor Shaikh ${ }^{\mathrm{c}}$, Bertrand Laratte ${ }^{\mathrm{d}, \mathrm{e}, \mathrm{f}}$, \\ Steven B. Young ${ }^{\mathrm{c}}$, Guido Sonnemann ${ }^{\mathrm{a}, \mathrm{b}, *}$ \\ ${ }^{\text {a } U n i v e r s i t e ́ ~ d e ~ B o r d e a u x, ~ I S M, ~ U M R ~ 5255, ~ F-33400 ~ T a l e n c e, ~ F r a n c e ~}$ \\ ${ }^{\mathrm{b}}$ CNRS, ISM, UMR5255, F-33400 Talence, France \\ ${ }^{\mathrm{c}}$ School of Environment, Enterprise and Development, University of Waterloo, 200 University Avenue West, Waterloo, Ontario, Canada \\ ${ }^{\mathrm{d}}$ Arts et Metiers Institute of Technology, University of Bordeaux, CNRS, Bordeaux INP, INRAE, I2M Bordeaux, F-33400 Talence, France \\ ${ }^{\mathrm{e}}$ Department of Industrial Engineering, Ondokuz Mayls University, 55139 Samsun, Turkey \\ ${ }^{\mathrm{f}}$ APESA-Innovation, F-40220 Tarnos, France
}

Keywords:

Life cycle assessment

Life cycle sustainability assessment

Critical raw materials

Criticality assessment

Circular economy

Domestic recycling
The Geopolitical Supply Risk method, originally developed by Gemechu et al. (2016) and subsequently extended by Helbig et al. (2016a) and Cimprich et al. (2017, 2018), is aimed at incorporating supply risk assessment of "critical raw materials" as a complement to environmental life cycle assessment (LCA) within life cycle sustainability assessment (LCSA). In this article, we further extend the method to consider the risk-mitigating potential of domestic recycling - thus advancing considerations of "circular economy" strategies for managing materials criticality. Our method captures two mechanisms through which domestic recycling can affect supply risk: a reduction in total imports (the "reduction effect"), and a potential redistribution of the import supply mix (the "redistribution effect"). We consider a range of outcomes from a best-case scenario (displacing imports from the riskiest trade partners) to a worst-case scenario (displacing imports from the least risky trade partners). Using our recently developed automated calculation tool, which significantly improves the practical applicability of the method by facilitating the otherwise burdensome computations required, we test and demonstrate our method on 13 raw materials used for information and communication technologies in the European Union. Thus, we test the notion that recycling mitigates supply risk. The reality is more complex. To maximize risk mitigation, recycling should ideally take place domestically, recycled material should be reinserted into the domestic economy, and the import supply mix should be considered, especially given that the redistribution effect sometimes exceeds the reduction effect.

\section{Introduction}

Life cycle assessment (LCA) is a widely used methodological approach for evaluating the environmental impacts of products and services. The international standards for LCA (ISO 2006a, 2006b) structure the methodology around a framework comprising four interrelated and iterative phases: (1) goal and scope definition, (2) life cycle inventory (LCI) of resource use and emissions, (3) life cycle impact assessment (LCIA), which assigns "characterization factors" to the LCI results, and (4) life cycle interpretation. Of the three "areas of protection" (AoPs) conventionally addressed in the LCIA phase - human health, ecosystem quality, and "natural resources" - the third is the least mature
(Dewulf et al., 2015). Although considerations of resource use - particularly regarding mineral resources - are commonly included in LCIA methods, differences in problem formulation and modeling have fueled debates among method developers and confusion among LCA practitioners (Dewulf et al., 2015; Drielsma et al. 2016, Sonderegger et al., 2020). Therefore, in 2017, the Life Cycle Initiative, hosted by UN Environment, established an expert Task Force that reviewed existing LCIA methods addressing aspects of mineral resource use (Sonderegger et al., 2020). Through discussions at a Pellston ${ }^{\circledR}$ workshop, another group (which included a subset of the Task Force members) formulated recommendations, at different levels of recommendation, for application-dependent use of existing methods and areas for further

\footnotetext{
* Corresponding author. Université de Bordeaux, ISM, UMR 5255, F-33400 Talence, France.

E-mail address: guido.sonnemann@u.bordeaux.fr (G. Sonnemann).
} 
methodological development (Berger et al., 2020).

Alongside conventional approaches aimed at assessing long-term mineral resource "depletion" (e.g., as in the widely used Abiotic Depletion Potential (ADP) method (Van Oers and Guineé, 2016)) and theoretical increases in the "future efforts" needed for resource extraction and processing, the Task Force also considered newer approaches aimed at assessing the supply risk of "critical raw materials" over shorter timeframes. The subject of raw material "criticality" typically conceptualized as a function of the likelihood and severity of raw material supply disruptions (Erdmann and Graedel, 2011; Ericsson et al., 2019; Graedel et al., 2012; Graedel and Reck, 2016; Achzet and Helbig, 2013; Helbig et al., 2016b; European Commission, 2017; Dewulf et al., 2016) - has attracted growing research and policy interest given the diversity of raw materials used in modern products and the complexity of globalized supply-chains. Recognizing the relevance of criticality, a dedicated subgroup of the Task Force published a separate review article (Cimprich et al., 2019) that provides deeper discussion of the three "supply risk methods" considered within the Task Force: the Economic Scarcity Potential (ESP) method (Schneider et al., 2014), its successor, the Integrated Method to Assess Resource Efficiency (ESSENZ) (Bach et al., 2016), and - our focus in this article - the Geopolitical Supply Risk (GeoPolRisk) method (Gemechu et al., 2015; Gemechu et al., 2016; Helbig et al., 2016; Cimprich et al., 2017, 2018). The GeoPolRisk method was developed as a complement to environmental LCA based on the framework developed by Sonnemann et al. (2015) that conceptualizes the integration of criticality assessment into life cycle sustainability assessment (LCSA; a conceptual extension of LCA that aims to incorporate social and economic sustainability dimensions alongside the environmental dimension).

Compared to the ESP and ESSENZ methods, the GeoPolRisk method mainly differs in that (i) it provides country-specific supply risk characterization factors rather than global values and (ii) it focuses on a single factor - geopolitical (in)stability of trade partners - as a "source" of supply risk, setting aside other considerations like co-production (e.g., when a "companion" metal is produced alongside a "host" metal), price volatility, demand growth, trade barriers, and feasibility of exploration projects (Cimprich et al., 2019). Upon consideration of their respective strengths and limitations, the Task Force made several recommendations for further development of the three "supply risk" methods. The recommendations include (i) increased spatial resolution of characterization factors (e.g., by assessing regional and firm-level supply risk factors not captured by existing global or country-level assessments), (ii) improved modeling of multiple supply-chain stages (e.g., mining, smelting, and refining of metals, and perhaps even downstream product fabrication and manufacturing stages), and (iii) assessment of the risk-mitigating potential of material recycling (Cimprich et al., 2019).

In this article, we address the third point by extending the GeoPolRisk method to consider the risk-mitigating potential of domestic recycling (as we will further explain and demonstrate, "domestic" is the keyword here) - thus advancing considerations of "circular economy" strategies for managing materials criticality (as highlighted in a recent Perspective paper (Tercero Espinoza et al., 2020) published in this journal by members (including two of the authors of the present article) ${ }^{1}$ of the International Round Table on Materials Criticality (IRTC) - an international collaboration funded through the European Institute of Innovation and Technology (EIT) Raw Materials consortium). Our extended GeoPolRisk method captures two mechanisms through which domestic recycling can affect raw material supply risk: first, a reduction in total imports (the "reduction effect"), and second, a potential redistribution of the import supply mix (the "redistribution effect"). We consider a range of outcomes from a

\footnotetext{
${ }^{1}$ Steven B. Young and Guido Sonnemann
}

best-case scenario (in which domestically recycled raw materials displace imports from the riskiest trade partners first) to a worst-case scenario (in which domestically recycled raw materials displace imports from the least risky trade partners first). Using our recently developed automated calculation tool, which significantly improves the practical applicability of the GeoPolRisk method by facilitating the otherwise burdensome computations required, we test and demonstrate our enhanced method on 13 raw materials used for, among other things, developing and strengthening the information and communication technologies (ICT) sector in the European Union. The ICT sector constitutes $4.8 \%$ of the EU economy and accounts for $17 \%$ of expenditures in research and development within the EU (European Commission, 2019). The increasing use and relevance of a wide range of products in the ICT category raises questions about the amount and variety of critical raw materials needed for these applications; moreover, there are growing concerns about the potential recovery of these materials from end-of-life products in the EU (Horta, 2019). As the GeoPolRisk method is applied to raw materials trading on a country or regional level, the results for the 13 raw materials used in the ICT sector - itself an interesting and relevant case study - are equally applicable to other sectors of the European economy that may use these same raw materials.

Thus, we test the notion - widely reflected in the literature on critical raw materials (Erdmann and Graedel, 2011; Graedel and Reck, 2016; Gaustad et al., 2017) - that recycling mitigates raw material supply risk. The reality is more complex. To maximize risk mitigation, recycling should ideally take place domestically, the recycled material should be reinserted into the domestic economy, and the import supply mix should be considered - especially given that the redistribution effect sometimes exceeds the reduction effect.

\section{Materials and methods}

The GeoPolRisk method, originally developed by Gemechu et al. (2016), is aimed at incorporating raw material supply risk assessment as a complement to environmental LCA within the framework of LCSA. The method takes the perspective of a given macroeconomic unit (typically a country or region; henceforth referred to as a "country") importing a given commodity from various trade partners. The geopolitical (in)stability, measured by the Worldwide Governance Indicator - Political Stability and Absence of Violence and Terrorism (WGI-PV), of the trade partners is considered the "source" of supply risk. Thus, the first iteration of the method calculated the GeoPolRisk, of commodity A imported to country c, according to Eq. (1) (for further discussion, see Gemechu et al., 2016).

GeoPolRisk $_{A c}=H_{H} * \sum_{i} \frac{g_{i}^{*} f_{A i c}}{F_{A c}}$

Where

$\mathrm{HHI}_{\mathrm{A}}=$ Herfindahl-Hirschman Index (Herfindahl, 1950; Hirschman, 1945) for commodity A, calculated as the sum of the squared production shares of all producing countries $g_{i}=$ geopolitical (in)stability of country $i$, measured by the Worldwide Governance Indicator - Political Stability and Absence of Violence and Terrorism (WGI-PV), transformed to a $0-1$ scale $\mathrm{f}_{\text {Aic }}=$ imports of commodity A from country $\mathrm{i}$ to country $\mathrm{c}$

$\mathrm{F}_{\mathrm{Ac}}=$ total imports of commodity A to country c

The next iteration, as detailed in Helbig et al. (2016a), advanced the method in two ways: (i) by accounting for domestic production - which by definition is not dependent on imports and thus is considered "riskfree" from a geopolitical perspective - and (ii) by extending the calculation to multiple supply-chain stages (as trading occurs, and risks are incurred, at each stage - e.g., mining, smelting, and refining of metals). For simplicity, only the "single-stage" calculation is shown here (Eq. (2)). 
GeoPolRisk $_{A c}=H H I_{A} * \sum_{i} \frac{g_{i} * f_{A i c}}{p_{A c}+F_{A c}}$

Where

$\mathrm{HHI}_{\mathrm{A}}=$ Herfindahl-Hirschman Index for commodity A, calculated as the sum of the squared production shares of all producing countries $\mathrm{g}_{\mathrm{i}}=$ geopolitical (in)stability of country $\mathrm{i}$, measured by the Worldwide Governance Indicator - Political Stability and Absence of Violence and Terrorism (WGI-PV), transformed to a $0-1$ scale $\mathrm{f}_{\text {Aic }}=$ imports of commodity A from country i to country $\mathrm{c}$

$\mathrm{F}_{\mathrm{Ac}}=$ total imports of commodity $\mathrm{A}$ to country $\mathrm{c} \mathrm{p}_{\mathrm{Ac}}=$ domestic production of commodity A in country $\mathrm{c}$

Subsequently, we considered how to link the GeoPolRisk indicator to the functional unit of a given end-product in LCA (Cimprich et al., 2017, 2018). For simplicity, we did so only with the "single-stage" calculation (per Eq. (2)). We also recognized that, in accordance with classical risk theory (Gloser et al., 2015; Frenzel et al., 2017), the previous iterations of the GeoPolRisk method are more accurately described as measuring supply disruption probability as opposed to supply disruption risk (the latter being a function of probability and vulnerability). Accordingly, we adjusted the terminology in this iteration of the method, which, for reasons discussed by Cimprich et al. (2017, 2018), "cancels out" the amount of the commodity used to make the end-product (Eq. (3)).

GeoPolRisk $k_{A P c}=m_{A P c}{ }^{*} C F_{A P c}=\frac{m_{A P c}{ }^{*} G e o P o l_{A c}{ }^{*} S_{A P c}}{m_{A P c}}$

Where

GeoPolRisk $_{\mathrm{APc}}=$ geopolitical supply risk category indicator (i.e., equivalent to LCIA result) for commodity A needed to produce product $\mathrm{P}$ in country $\mathrm{c} \mathrm{m}_{\mathrm{APc}}=$ amount of commodity A (i.e., from life cycle inventory) needed to produce product $\mathrm{P}$ in country c (note: if $\mathrm{m}_{\mathrm{APc}}=0$, $\mathrm{CF}_{\mathrm{APc}}=0$ )

$\mathrm{CF}_{\mathrm{APc}}=$ geopolitical supply risk characterization factor for commodity A needed to produce product $\mathrm{P}$ in country $\mathrm{c}$

$\mathrm{GeoPol}_{\mathrm{Ac}}=$ geopolitical supply disruption probability for commodity A imported to country c (calculated per Eq. (2)) $\mathrm{s}_{\mathrm{APc}}=$ « substitutability » of commodity A needed to produce product $\mathrm{P}$ in country c (i.e., " substitutability » serves to mitigate supply risk; all else being equal, the more substituable a commodity, the lower the vulnerability to supply disruption).

In this article, we further extend the GeoPolRisk method to consider the risk-mitigating potential of domestic recycling. "Domestic" is the keyword here; materials recycled in foreign countries are considered imports under the GeoPolRisk method, whereas, per Eq. (2), domestically recycled materials (of comparable quality to primary raw materials) are considered a source of domestic production $\left(\mathrm{p}_{\mathrm{Ac}}\right)$ - which in turn is considered "risk-free" from a geopolitical perspective. Thus, holding the total material use (i.e., $\mathrm{p}_{\mathrm{Ac}}+\mathrm{F}_{\mathrm{Ac}}$ ) constant, an increase in domestic recycling implies a reduction of total imports. But from which trade partners does this reduction come from? As illustrated in Fig. 1, the reduction of total imports - achieved through domestic recycling can change the import supply mix (i.e., import shares from various trade partners).

Thus, as illustrated in Fig. 2, our extended GeoPolRisk method captures two mechanisms through which domestic recycling can affect raw material supply risk: first, a reduction in total imports (the "reduction effect"), and second, a potential redistribution of the import supply mix (the "redistribution effect"). We consider a range of outcomes from a best-case scenario (BCS; in which domestically recycled raw materials displace imports from the riskiest trade partners first measured by their WGI-PV scores) to a worst-case scenario (WCS; in which domestically recycled raw materials displace imports from the least risky trade partners first). Fig. 2 illustrates the range of possible GeoPolRisk values for a given domestic recycling rate under all scenarios for the import supply mix (i.e., from the BCS to the WCS). The
WCS and BCS correspond to the highest and lowest GeoPolRisk values, respectively, for a given recycling rate.

To test and demonstrate our extended GeoPolRisk method, we compiled a set of 13 raw materials (or groups of raw materials) used for, among other things, developing and strengthening the information and communication technologies (ICT) sector in the European Union. The complete list was obtained by crossmatching the Report on Critical Materials for the European Union (European Commission, 2017) and the raw materials listed in the report on material efficiency of the personal computers product group (Tecchio et al., 2018).

Four main pieces of information are required to calculate the GeoPolRisk values under our extended method: production volumes of each producing country, geopolitical (in)stability of each trade partner country, import volumes from each trade partner, and domestic recycling rates. We measured geopolitical instability using the country WGI-PV scores available from the World Bank (2019). We normalized the values on a 0 to 1 scale, with 0 being the most stable and 1 being the most unstable. The full set of WGI-PV scores, for all countries producing the 13 raw materials, is provided in the supplementary material. Raw material production and trade data were primarily obtained from the United States Geological Survey (USGS) annual Mineral Commodity Summaries (USGS, 2016,2017, 2018) and the United Nations Comtrade Database (UN, 2019) respectively. To fill gaps in these datasets for some raw materials (namely germanium, iridium and ruthenium), we referred to the Critical Raw Materials Factsheets from the European Commission (2017). Table 1 provides an overview of the data sources used to calculate the trade and production components of GeoPolRisk for the EU in 2016 (i.e., primary production by country and the import shares of each trade partner) for each raw material (or group). Grouping some raw materials - namely gallium group metals, platinum group metals (PGMs), and rare earth elements (REEs) - was necessary given data limitations.

Given the lack of data on domestic recycling of manufacturing scrap in the EU, we use the most recent values (i.e., from 2016) for the "endof-life recycling input rate" (EoL-RIR), available from Eurostat (2017), as a conservative estimate of the total supply of domestically recycled materials in the EU. The EoL-RIR is defined as the ratio between the sum of flows of secondary material recovered from end-of-life products and reinserted into the EU economy through domestic recycling, and the sum of supply flows from both primary and secondary sources (domestic and imported).

Previous applications of the GeoPolRisk method have been conducted using basic spreadsheet software. We have found this approach to be computationally burdensome. For example, testing the multi-stage GeoPolRisk method on a relatively straightforward three-stage supplychain for polyacrylonitrile carbon fiber precursor resulted in over 60,000 possible supply-chain paths (Helbig et al., 2016a). The calculation spreadsheet developed by Cimprich et al. (2018) in connection to an LCA case study of dental X-ray equipment - despite using the simpler "single-stage" calculation (i.e., per Eq. (3)) - was nearly $80 \mathrm{MB}$ in size (Cimprich, 2017). Therefore, to facilitate the calculations, we developed a novel web-based application using the Python programming language (Shaikh, 2020). Among other functionalities, this new tool allows users to quickly and easily calculate GeoPolRisk values for a given country, sourcing a given raw material, under a range of domestic recycling rates. We continue to develop and refine the tool, and we intend to make it freely and publicly accessible.

\section{Results}

Before presenting our full set of calculated GeoPolRisk values for all 13 raw materials (or raw material groups), we highlight the group of "other PGMs" (in Fig. 3) as an example that clearly illustrates the two mechanisms through which domestic recycling affects supply risk: the reduction effect (seen as the difference between the GeoPolRisk value at 0\% EoL-RIR and the WCS for the import supply mix) and the 


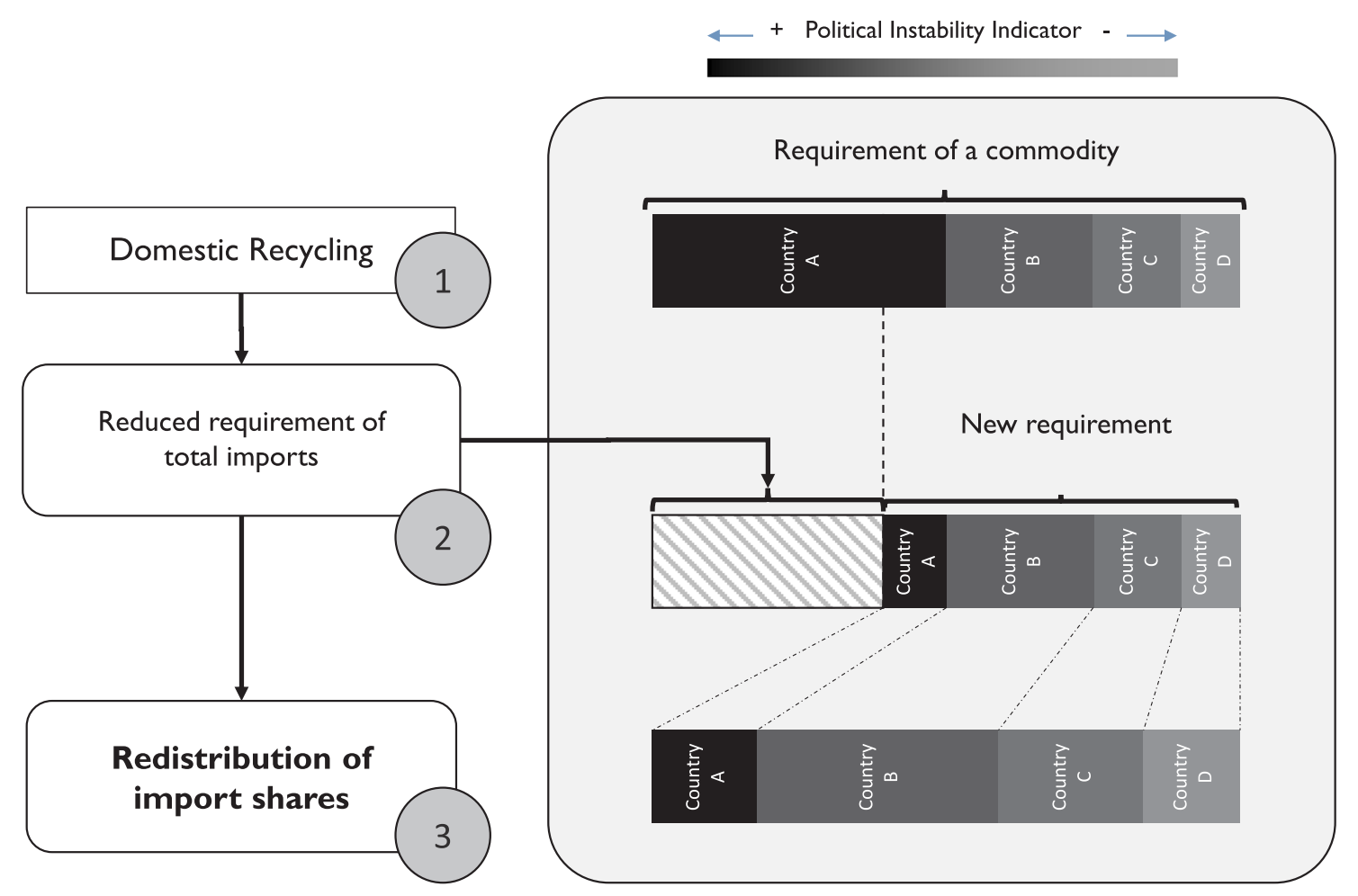

Fig. 1. - The "redistribution effect" of domestic recycling on the import supply mix of a commodity.

redistribution effect (seen as the difference between the WCS and the BCS).

In Fig. 4, we present the GeoPolRisk results for all 13 raw materials (or raw material groups) for values of the EoL-RIR ranging from $0 \%$ to $50 \%$; results for values of the EoL-RIR higher than $50 \%$ are available in supplementary material. For platinum, palladium, and "other PGMs," the redistribution effect is greater than the reduction effect at the present EoL-RIR. For magnesium and cobalt, in contrast, the reduction effect is greater than the redistribution effect - to the point where the latter is indiscernible. In the case of magnesium, this result reflects the present import supply mix to the EU, which relies heavily on China and Iran as the largest trade partners, both of which are relatively unstable countries (as measured by their relatively high WGI-PV values). In the case of cobalt, it can be explained by highly concentrated production (reflected in a relatively high HHI value) - namely in the Democratic Republic of Congo (which also has a high WGI-PV value). The magnitude of the redistribution effect mainly depends on the variation of WGI-PV values between various trade partners (see supplementary material for a full set of WGI-PV values for all countries producing the analyzed raw materials); the greater the variation, the greater the

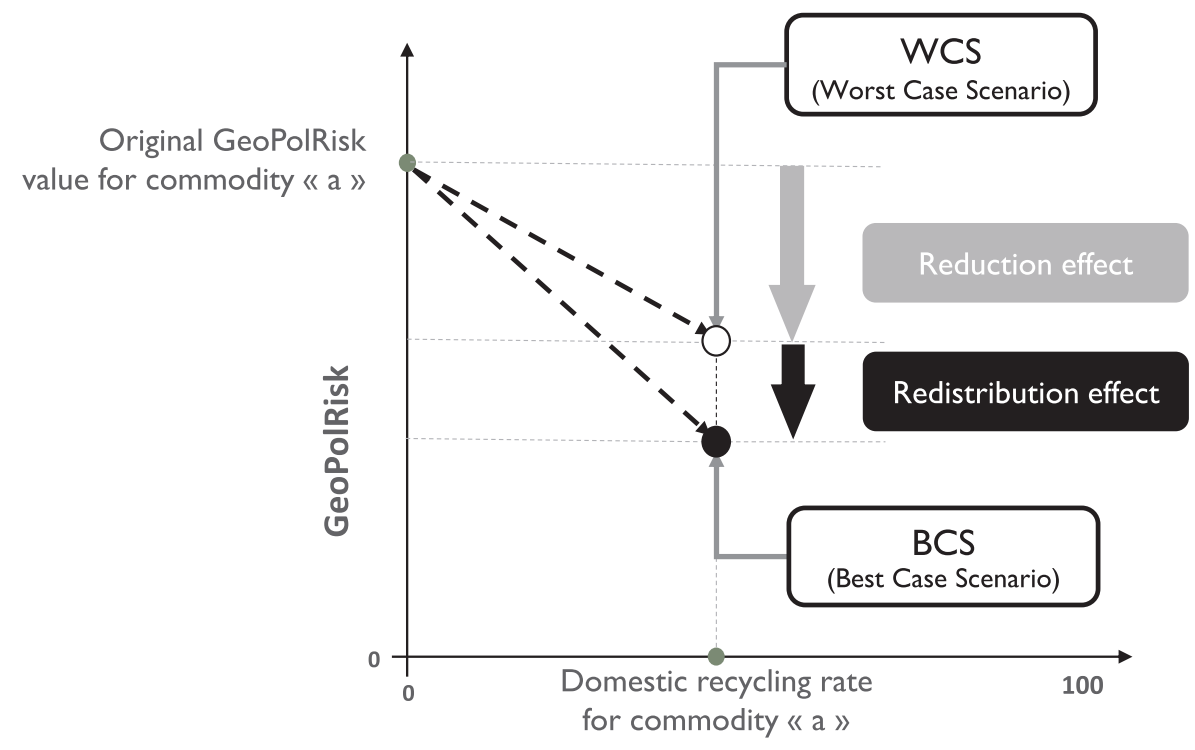

\section{Domestic recycling rate (\%)}

Fig. 2. - GeoPolRisk values for a given domestic recycling rate under a range of scenarios for the import supply mix. 
Table 1

Data sources (production and trade) for calculating GeoPolRisk of analyzed raw materials and raw material groups for the European Union in 2016.

\begin{tabular}{|c|c|c|c|c|}
\hline Raw material & Source for production data & Source for trade data & Notes & Label used in this article \\
\hline Berylium & USGS & Comtrade & - & berylium \\
\hline Borates & USGS (boron as proxy) & Comtrade & - & borates \\
\hline Cobalt & USGS & Comtrade & - & cobalt \\
\hline Germanium & USGS & $\begin{array}{l}\text { EC - Critical Raw Materials } \\
\text { FactSheets }\end{array}$ & - & germanium \\
\hline Magnesium & USGS & Comtrade & - & magnesium \\
\hline Natural graphite & USGS & Comtrade & - & natural graphite \\
\hline Palladium & USGS & Comtrade & - & palladium \\
\hline Platinum & USGS & Comtrade & - & platinum \\
\hline Silicon metal & USGS & Comtrade & - & silicon metal \\
\hline Tantalum & USGS & Comtrade & - & tantalum \\
\hline Gallium & USGS & Comtrade (Aggregated as Ga, Hf, In, & $\mathrm{Zr}$ and $\mathrm{Rh}$ added to the group to match & gallium group metals \\
\hline Hafnium & $\begin{array}{l}\text { USGS (aggregated with } \\
\text { zirconium) }\end{array}$ & $\mathrm{Rh}$ and $\mathrm{Nb})$ & available information & \\
\hline Indium & USGS & & & \\
\hline Niobium & USGS & & & \\
\hline $\begin{array}{l}\text { Iridium } \\
\text { Ruthenium }\end{array}$ & $\begin{array}{l}\text { EC - Critical Raw Materials } \\
\text { FactSheets }\end{array}$ & $\begin{array}{l}\text { Comtrade (aggregated as Ir, Os and } \\
\mathrm{Ru} \text { ) }\end{array}$ & Os production disregarded & other platinum group metals \\
\hline $\begin{array}{l}\text { Dysprosium } \\
\text { Erbium }\end{array}$ & $\begin{array}{l}\text { USGS (Aggregated as REEs and } \\
\text { Yttrium) }\end{array}$ & Comtrade (Aggregated as REE) & $\begin{array}{l}S c \text { production added to the group to match } \\
\text { available information }\end{array}$ & rare earth elements (REEs) \\
\hline \multicolumn{5}{|l|}{ Gadolinium } \\
\hline \multicolumn{5}{|l|}{ Ytterbium } \\
\hline \multicolumn{5}{|l|}{ Neodymium } \\
\hline \multicolumn{5}{|l|}{ Praseodymium } \\
\hline \multicolumn{5}{|l|}{ Samarium } \\
\hline \multicolumn{5}{|l|}{ Terbium } \\
\hline Yttrium & USGS (aggregated with REEs) & Comtrade (Aggregated with Sc) & & \\
\hline
\end{tabular}

potential redistribution of the import supply mix towards more stable trade partners. A high HHI value indicates that production is highly concentrated in a few countries - thus limiting the potential for redistribution of the import supply mix - but does not in itself result in a high GeoPolRisk value, as that also depends on the geopolitical instability of trade partners.

In the case of tantalum and germanium, the present EoL-RIR is low enough that neither the reduction effect nor the redistribution effect are significant - though they become increasingly significant at higher recycling rates (e.g., a 30\% EoL-RIR, combined with strategic redistribution of the import supply mix, could reduce the GeoPolRisk of germanium to about 0.2 , compared to the present value of 0.3 ). In the case of beryllium, borates, cobalt, gallium group metals, and silicon metal, the EoL-RIR is presently $0 \%$, so the GeoPolRisk values are the same as they would be if calculated per our original method (as in Eq. (2)). However, except for beryllium (for which production is dominated by the U.S., a relatively stable country), our results again suggest that domestic recycling has significant risk-mitigating potential, especially when the import supply mix is redistributed towards more stable trading partners. Silicon metal, for example, is not currently recovered from post-consumer waste given that many of the applications of this commodity have a dissipative nature (e.g. additives in coating processes), but recycling processes are being developed for some applications (European Commission, 2017). Given data limitations, we assume that the EoL-RIR of natural graphite and REEs is presently $0 \%$; nonetheless, our enhanced GeoPolRisk method - with the aid of our automated calculation tool - enables us to illustrate the potential risk mitigation that could be achieved through increased domestic recycling rates, especially when combined with redistribution of the import supply mix.

\section{Discussion}

The application of our extended GeoPolRisk method to 13 raw materials (or groups of raw materials) used for, among other things, information and communication technologies (ICT) in the European Union supports the notion - widely reflected in the literature on critical raw materials - that recycling can mitigate raw material supply risk.

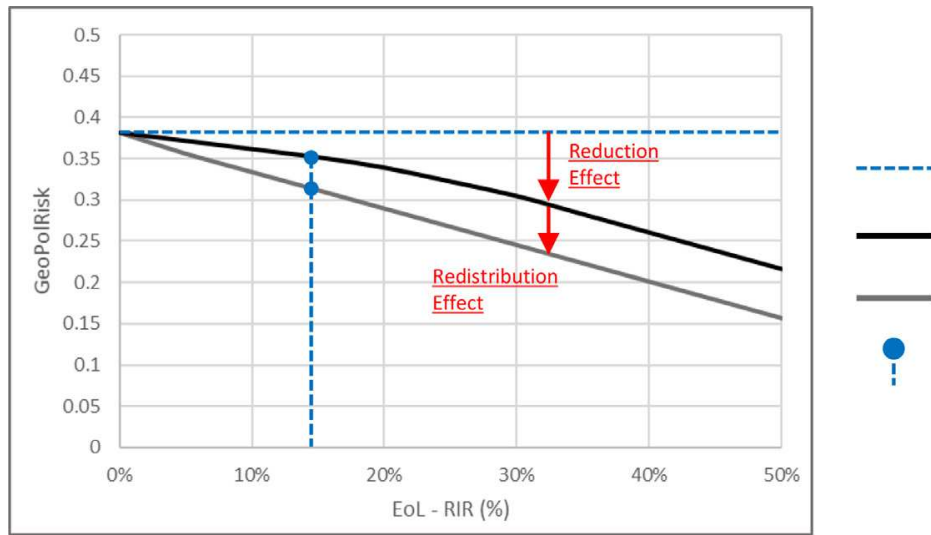

GeoPolRisk value at $0 \%$ EoL.RIR

WCS (Worst Case Scenario Curve)

BCS (Best Case Scenario Curve)

GeoPolRisk values at current EoL-RIR

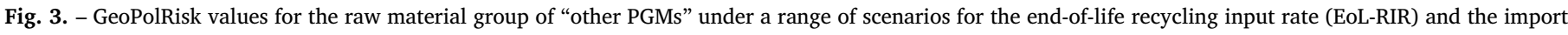
supply mix. 

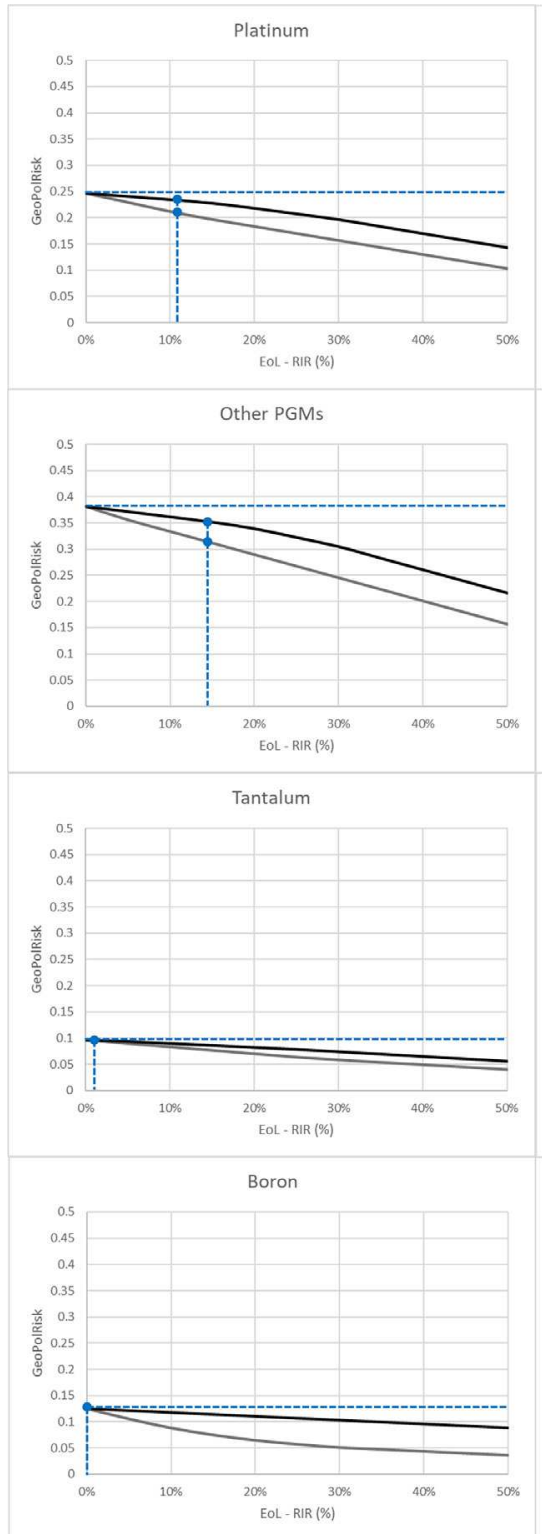
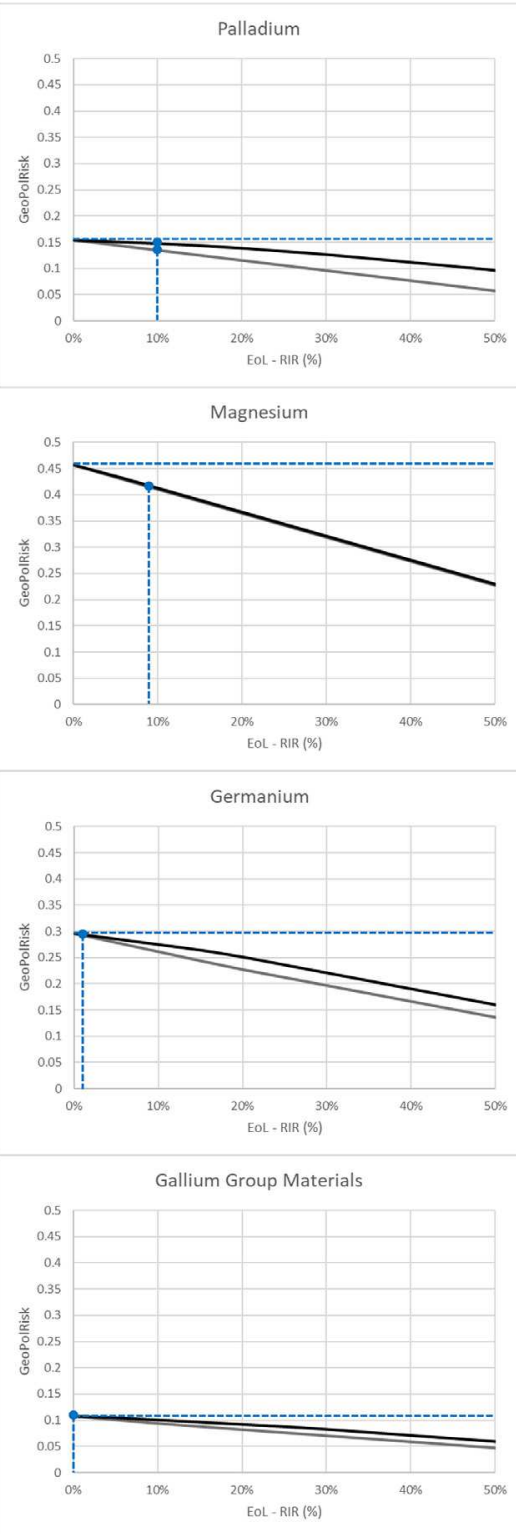
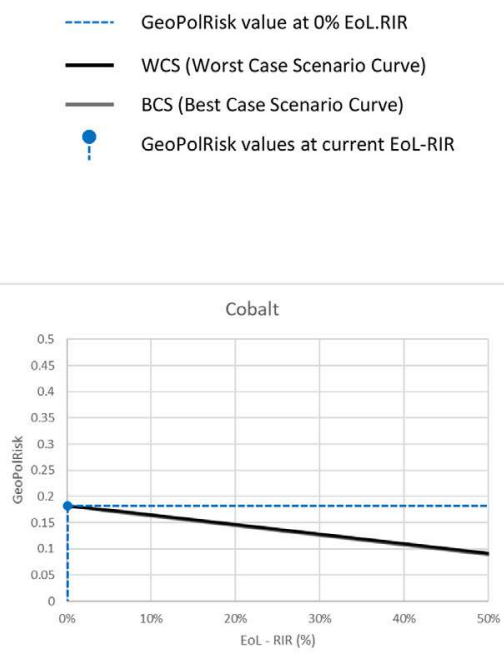

Berylium

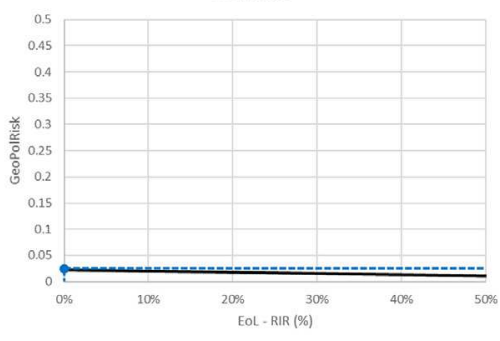

Silicon Metal

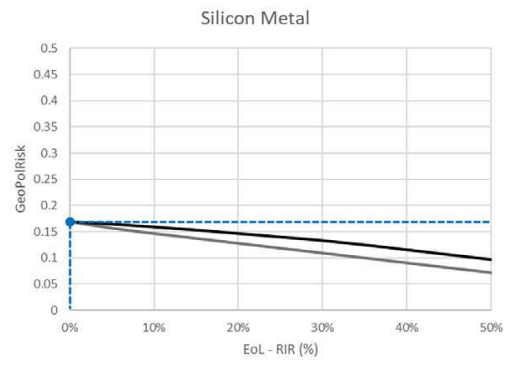

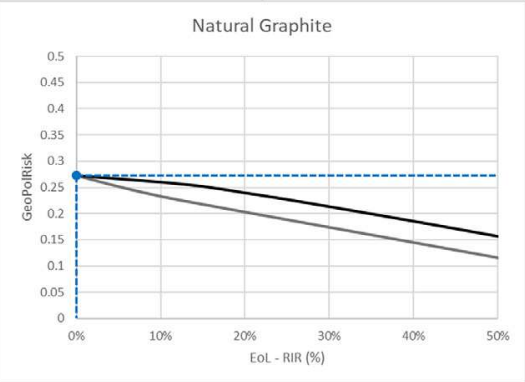

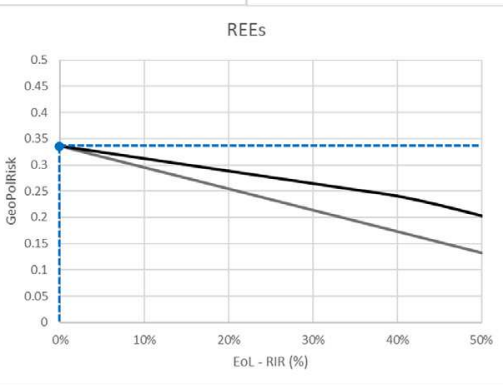

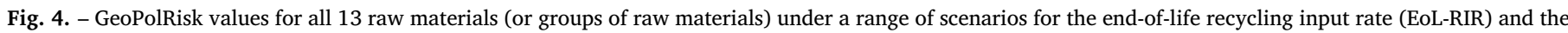
import supply mix.

But there is more to the story. As in other supply risk assessment methods developed with an LCA perspective, like the Economic Scarcity Potential (ESP; Schneider et al., 2014) and ESSENZ (Bach et al., 2016), we consider that recycling can mitigate supply risk by relieving pressure on primary sourcing. However, given the regionalized nature of the GeoPolRisk indicator, we add another layer to the assessment by considering the relative geopolitical (in)stability of both primary and secondary sources. Our extended GeoPolRisk method considers two mechanisms through which recycling can affect supply risk: first, a reduction of total imports (the "reduction effect"), and second, a potential redistribution of the import supply mix (the "redistribution effect"). Thus, to maximize risk mitigation, recycling should ideally take place domestically (or recycled materials should be imported from relatively stable countries), and the recycled material should be reinserted into the domestic economy. Importing recycled materials from foreign economies might bring environmental benefits compared to using virgin materials, but this does not maximize the mitigation of geopolitical-related supply risk. In fact, it could exacerbate supply risk 
if the recycled materials are imported from geopolitically unstable countries or regions. To further mitigate supply risk, the import supply mix should be considered - especially given that the redistribution effect sometimes exceeds the reduction effect.

Our extended GeoPolRisk method is subject to several limitations in theory and practice. First, from a practical perspective, it can be difficult to obtain the necessary production and trade data with sufficient granularity for all raw materials under consideration. The UN Comtrade database, for example, often lacks an appropriate commodity code (e.g., the rare earth metals neodymium and gadolinium), or aggregates multiple commodities into a single commodity code (e.g., HS 261590 for "niobium, tantalum, vanadium ores and concentrates"). Therefore, in our case, we aggregate some raw materials into groups (namely "other PGMs," gallium group metals, and REEs), which masks variations in supply risk between commodities within these groups. There can also be significant uncertainty around domestic recycling rates, which are influenced by a variety of factors - including, among other things, current metal stocks, future demand, quality policies, technology restrictions, and economic feasibility (UNEP, 2013). We used the end-of-life recycling input rate (EoL-RIR) as a conservative estimate, though this value is not available for all raw materials. However, as demonstrated through our case study, our extended GeoPolRisk method - facilitated by our new calculation tool - can simulate what the riskmitigating effect could be under any given recycling rate. The results of our case study suggest that increased domestic recycling rates, combined with strategic redistribution of the import supply mix, can be an effective risk-mitigation strategy. Problems of data availability and quality, though limiting in practice, do not constitute a theoretical limitation of the methodology itself.

The theoretical limitations of the GeoPolRisk method have been extensively discussed in our earlier publications (Gemechu et al., 2016a, b; Helbig et al., 2016a; Cimprich et al., 2017, 2018) and in the Life Cycle Initiative Task Force on Mineral Resources (Cimprich et al., 2019). In particular, while the methodological advancement we present in this article addresses one of the three main Task Force recommendations for "supply risk methods" (i.e., incorporating considerations of material recycling), the other two (i.e., increased spatial resolution and improved modeling of multiple supply-chain stages) remain largely open questions. With respect to spatial resolution, the GeoPolRisk method models supply risk as a function of commodity trading between macroeconomic units (i.e., countries or regions), whereas supply-chains actually comprise market relationships between microeconomic units (i.e., firms). The same argument applies to environmental and social sustainability aspects in supply-chains (Goldstein and Newell, 2020). With respect to modeling multiple supply-chain stages, though we have previously developed an extension of the GeoPolRisk method for this purpose (Helbig et al., 2016a), we have tested this extension on only (part of) a single product system (polyacrylonitrile used as a precursor for carbon fiber production), and, from an LCA perspective, it remains unclear how to link the multi-stage GeoPolRisk calculation to the functional unit of a given product. Finally, the GeoPolRisk method can be considered equivalent to a "midpoint" approach in LCIA, as it serves to indicate (or at least give a proxy for) the relative likelihood of geopolitically-induced supply disruptions of a given raw material for a given macroeconomic unit. Further development could extend the methodology to an "endpoint" approach (e.g., to assess the impacts of supply disruptions as manifested in physical raw material shortages and/or price spikes) for the "natural resources" AoP in the life cycle sustainability assessment (LCSA) framework.

Limitations notwithstanding, our extension of the GeoPolRisk method directly addresses the Task Force recommendation to incorporate the potential risk-mitigating effects of material recycling into "supply risk methods." Thus, we advance considerations of "circular economy" strategies for critical raw materials (e.g., as seen in a recent Perspective paper published in this journal by members
(Tercero Espinoza et al., 2020) of the International Round Table on Materials Criticality (IRTC)) and in policy initiatives like the EU Circular Economy Plan, in which domestic recycling is highlighted as a key supply security strategy for reducing import dependency (European Commission, 2011; European Commission, 2015; Mathieux et al., 2018). Further, our automated calculation tool significantly improves the practical applicability of the GeoPolRisk method by facilitating the otherwise burdensome computations required.

\section{Conclusions}

In this article, we have further enhanced the GeoPolRisk method originally developed by Gemechu et al. (2016) and subsequently extended by Helbig et al. (2016a) and Cimprich et al. $(2017,2018)$ - to consider the potential for domestic recycling to mitigate supply risk of "critical raw materials". Thus, we have addressed one of the main areas of methodological development highlighted within the work of the Life Cycle Initiative Task Force on Mineral Resources (Cimprich et al., 2019; Sonderegger et al., 2020; Berger et al., 2020); at the same time, we advance considerations of "circular economy" strategies for materials criticality. Using our recently developed automated calculation tool, which facilitates the otherwise burdensome computations involved, we have tested and demonstrated our method on 13 raw materials (or groups of raw materials) used for, among other things, developing and strengthening the information and communication technologies (ICT) sector in the European Union. As the GeoPolRisk method is applied to raw materials trading on a country or regional level, the results for the 13 raw materials used in the ICT sector - itself an interesting and relevant case study - are equally applicable to other sectors of the European economy that may use these same raw materials.

As discussed in detail by Cimprich et al. (2019), further methodological development is needed to better reflect the complex multi-stage structure of globalized supply-chains, and to link a multi-stage GeoPolRisk indicator to the functional unit of a given end-product. The GeoPolRisk method, like other "criticality assessment" methods - also remains subject to data limitations - particularly around recycling rates, primary production, and commodity trading (e.g., as reflected in our grouping of some commodities, like gallium group metals, PGMs, and REEs, used in the ICT sector). Further work could also increase the spatial resolution of the method (e.g., by applying the method on a company-level as opposed to a country-level) and extend it to an "endpoint" approach (e.g., to assess the impacts of supply disruptions as manifested in physical raw material shortages and/or price spikes).

Nonetheless, application of our extended GeoPolRisk method to the ICT sector supports the notion that recycling can mitigate raw material supply risk. However, the risk-mitigating effects are more complex than commonly assumed in the literature on critical raw materials. As captured in our method, we can discern two mechanisms through which domestic recycling can affect supply risk: first, a reduction of total imports (the "reduction effect"), and second, a potential redistribution of the import supply mix (the "redistribution effect"). We consider a range of outcomes from a best-case scenario (in which domestically recycled raw materials displace imports from the riskiest trade partners first) to a worst-case scenario (in which domestically recycled raw materials displace imports from the least risky trade partners first). Thus, the riskmitigating potential is maximized when recycling takes place domestically and the recycled material is reinserted into the domestic economy. Importing recycled materials from foreign economies might bring environmental benefits compared to using virgin materials, but this does not maximize the mitigation of geopolitical-related supply risk. In fact, it could exacerbate supply risk if the recycled materials are imported from geopolitically unstable countries or regions. To further mitigate supply risk, the import supply mix should be considered especially given that the redistribution effect sometimes exceeds the reduction effect. Thus, as demonstrated through the example of raw materials used in the European ICT sector, application of our extended 
GeoPolRisk method, facilitated by our automated calculation tool, can help industry and policy decision-makers to maximize the potential benefits of recycling critical raw materials.

\section{CRediT authorship contribution statement}

Jair Santillán-Saldivar: Conceptualization, Methodology, Investigation, Writing - original draft. Alexander Cimprich: Writing review \& editing. Noor Shaikh: Software, Data curation. Bertrand Laratte: Writing - review \& editing. Steven B. Young: Resources, Writing - review \& editing. Guido Sonnemann: Resources, Writing review \& editing, Supervision.

\section{Declaration of Competing Interest}

The authors declare that they have no known competing financial interests or personal relationships that could have appeared to influence the work reported in this paper.

\section{Acknowledgements}

We would like to thank the four anonymous reviewers who provided their time and expertise to improve upon our original submission.

\section{Supplementary materials}

Supplementary material associated with this article can be found, in the online version, at doi:10.1016/j.resconrec.2020.105108.

\section{References}

Achzet, B., Helbig, C., 2013. How to evaluate raw material supply risks—An overview. Resour. Policy 38, 435-447 2013.

Bach, V., Berger, M., Henßler, M., et al., 2016. Integrated method to assess resource efficiency - ESSENZ. J. Clean. Prod. 118-1302016.

Berger, M., Sonderegger, T., Alvarenga, R., et al., 2020. Mineral resources in life cycle impact assessment: part II - recommendations on application-dependent use of existing methods and on future method development needs. Int. J. Life Cycle Assess. https://doi.org/10.1007/s11367-020-01737-5. 2020.

Cimprich, A., 2017. From the outside in... Geopolitical Supply Risk and Life Cycle Assessment of Products. Master's thesis. University of Waterloo (Waterloo, Ontario, Canada).

Cimprich, A., Young, S.B., Helbig, C., Gemechu, E.D., Thorenz, A., Tuma, A., Sonnemann, G., 2017. Extension of geopolitical supply risk methodology: characterization model applied to conventional and electric vehicles. J. Clean. Prod. 754-763 2017.

Cimprich, A., Karim, K.S., Young, S.B., 2018. Extending the geopolitical supply risk method: material "substitutability" indicators applied to electric vehicles and dental X-ray equipment. Int. J. Life Cycle Assess.

Cimprich, A., Bach, V., Helbig, C., Thorenz, A., Schrijvers, D., Sonnemann, G., Young, S.B., Sonderegger, T., Berger, M., 2019. Raw material criticality assessment as a complement to environmental life cycle assessment: examining methods for product-level supply risk assessment. J. Ind. Ecol. 23, 1226-1236.

Erdmann, L., Graedel, T.E., 2011. Criticality of non-fuel minerals: a review of major approaches and analysis. Environ. Sci. Technol. 45, 7620-7630.

Dewulf, J., Benini, L., Mancini, L., Sala, S., Blengini, G.A., Ardente, F., Recchioni, M., Maes, J., Pant, R., Pennington, D., 2015. Rethinking the area of protection «natural resources » in life cycle assessment. Environ. Sci. Technol 49, 5310-5317.

Dewulf, J., Blengini, G.A., Pennington, D., P., Nuss, Nassar, N.T., 2016. Criticality on the international scene: quo Vadis? Resour. Policy 50, 169-176.

Ericsson, M., Drielsma, J., Humphreys, D., Storm, P., Weihed, P., 2019. Why current assessments of 'future efforts' are no basis for establishing policies on material use-A response to research on ore grades. Miner Econ. 32, 111-121.

European Commission, 2011. Roadmap to a Resource Efficient Europe (https://eur-lex. europa.eu/legal-content/EN/TXT/?uri = CELEX:52011DC0571). Accessed Nov, 2019.

European Commission, 2015. Closing the Loop - An eu action plan for the circular economy. (https://eur-lex.europa.eu/legal-content/EN/TXT/?uri = CELEX \%3A52015DC0614) Accessed Nov, 2019.

European Commission, 2017. Study on the review of the list of critical raw materials (https://publications.europa.eu/en/publication-detail/-/publication/08fdab5f-976611e7-b92d-01aa75ed71a1/language-en). Accessed Nov, 2019.

European Commission, 2019. ICT industry and ICT R\&D in Europe, 2019. (https://ec. europa.eu/jrc/en/research-topic/ict-rd-and-innovation). Accesssed Nov, 2019.

Eurostat, 2017. Contribution of recycled materials to raw materials demand - end-of-life recycling input rates (EOL-RIR). Accessed Mar, 2019.

Frenzel, M., Kullik, J., Reuter, M., Gutzmer, J., 2017. Raw material "criticality" - Sense or nonsense? J. Phys. D Appl. Phys. 50, 123002. https://doi.org/10.1088/1361-6463/ aa5b64.

Gaustad, G., Krystofik, M., Bustamante, M., Badami, K., 2017. Circular economy strategies for mitigating critical material supply issues. Resour. Conserv. Recycl. 135.

Gemechu, E.D., Helbig, C., Sonnemann, G., Thorenz, A., Tuma, A., 2015. Import-based indicator for the geopolitical supply risk of raw materials in life cycle sustainability assessments. J. Ind. Ecol. 20, 154-165 2015.

Gemechu, E.D., Sonnemann, G., Young., S.B., 2016. Geopolitical-related supply risk assessment as a complement to environmental impact assessment: the case of electric vehicles. Int. J. Life Cycle Assess 2016.

Glöser, S.L.T.E., Gandenberger, C., Faulstich, M., 2015. Raw material criticality in the context of classical risk assessment. Resour. Policy 44, 35-46 2015.

Goldstein, B., Newell, J.P., 2020. How to track corporations across space and time. Ecol Econ. 169, 1064922020.

Graedel, T.E., Barr, R., Chandler, C., Chase, T., Choi, J., Christoffersen, L., Friedlander, E., Henly, C., Jun, C., Nassar, N.T., Schechner, D., Warren, S., Yang, M.Y., Zhu, C., 2012. Methodology of metal criticality determination. Environ. Sci. Technol. 46, 1063-1070 2012.

Graedel, T.E., Reck, B.K., 2016. Six years of criticality assessments: what have we learned so far? J. Ind. Ecol. 20, 692-699.

Helbig, C., Gemechu, E.D., Pillain, B., Young, S.B., Thorenz, A., Tuma, A., Sonnemann, G., 2016 aa. Extending the geopolitical supply risk indicator: application of life cycle sustainability assessment to the petrochemical supply chain of polyacrylonitrilebased carbon fibers. J. Clean. Prod. 137, 1170-1178 2016.

Helbig, C., Wietschel, L., Thorenz, A., Tuma, A., 2016 bb. How to evaluate raw material vulnerability - an overview. Resour. Policy 48, 13-24 2016.

Herfindahl, O.C., 1950. Concentration in the Steel Industry (Doctoral Dissertation). Columbia University, New York.

Hirschman, A.O., 1945. National Power and the Structure of Foreign Trade. University of California Press, London, UK.

Horta, R., 2019. From waste management to supplier of secondary raw materials: development of indicators to support WEEE chain management - focus on the French system. Doctoral thesis. École Nationale Supérieure d'Arts et Métiers (Bordeaux, Gironde, France).

ISO (2006 a) . ISO 14040:2006 Environmental management — Life cycle assessment Principles and framework.

ISO (2006 b) . ISO 14044:2006 Environmental management — Life cycle assessment Requirements and Guidelines.

Mathieux, F., Ardente, F., Garbarino, E., Blagoeva, D., Blengini, G.A., Pavel, C., Torres De Matos, C., Solar, S., Nuss, P., Wittmer, D., Tzimas, E., Gawlik, B., Hamor, T., Orveillon, G., Saveyn, H., Bouraoui, F., Huygens, D., Alves Dias, P., Bobba, S., 2018. Critical raw materials and the circular economy. JRS Tech. Rep. https://op.europa. eu/en/publication-detail/-/publication/d0c609d2-f4ef-11e7-be11-01aa75ed71a1/ language-en Accessed Nov, 2019.

Schneider, L., Berger, M., Schüler-Hainsch, E., Knöfel, S., Ruhland, K., Mosig, J., Bach, V., Finkbeiner, M., 2014. The economic resource scarcity potential (ESP) for evaluating resource use based on life cycle assessment. Int. J. Life Cycle Assess. 19, 601-610 2014.

Shaikh, N., 2020. Tool to assess raw material social supply risks. Master's thesis. University of Waterloo, Waterloo, Ontario, Canada.

Sonnemann, G., Gemechu, E.D., Adibi, N., 2015. From a critical review to a conceptual framework for integrating the criticality of resources into life cycle sustainability assessment. J. Clean. Prod. 94, 20-34.

Sonderegger, T., Berger, M., Alvarenga, R., et al., 2020. Mineral resources in life cycle impact assessment-Part I: a critical review of existing methods. Int. J. Life Cycle Assess. https://doi.org/10.1007/s11367-020-01736-6. 2020.

Tecchio, P., Ardente, F., Marwede, M., Christian, C., Dimitrova, G., Mathieux, F., 2018. Analysis of material efficiency aspects of personal computers product group. JRC Tech. Rep. https://op.europa.eu/en/publication-detail/-/publication/9047e9dcfff2-11e7-b8f5-01aa75ed71a1/language-en Accessed Nov, 2019.

Tercero-Espinoza, L., Schrijvers, D., Chen, W., Dewulf, J., Eggert, R., Goddin, J., Habib, K., Hageluken, C., Hurd, A.J., Kleijn, R., Ku, A., Lee, M., Nansai, K., Nuss, P., Peck, D., Petavratzi, E., Sonnemann, G., van der Voet, E., Wager, P., Hool, A., 2020. Perspective: greater circularity leads to lower criticality, and other links between criticality and the circular economy. Resour. Conserv. Recycl 2020.

United Nations, 2019. UN comtrade database. (https://comtrade.un.org/) Accessed Mar, 2019.

UNEP, 2013. Metal recycling: opportunities, limits, infrastructure. In: Reuter, M.A., Hudson, C., van Schaik, A., Heiskanen, K., Meskers, C., Hagelüken, C. (Eds.), A Report of the Working Group On the Global Metal Flows to the International Resource Panel.

USGS, 2016. Mineral commodity summaries 2015. (https://www.usgs.gov/centers/ nmic/mineral-commodity-summaries) Accessed Jan, 2019.

USGS, 2017. Mineral commodity summaries 2016. (https://www.usgs.gov/centers/ nmic/mineral-commodity-summaries) Accessed Jan, 2019.

USGS, 2018. Mineral commodity summaries 2017. (https://www.usgs.gov/centers/ nmic/mineral-commodity-summaries) Accessed Jan, 2019.

Van Oers, L., Guineé, J., 2016. The abiotic depletion potential: background, updates, and future. Resources 5 (1), 16 .

World Bank. 2019. Worldwide Governance Indicators. (https://info.worldbank.org/ governance/wgi/) Accessed Nov, 2019. 